\title{
Legal Aspects of the Safety of Healthcare Professionals Working with Migrants
}

\author{
DALILA BRITO, IDALINA Vilela \& NoEMIA BESSA Vilela
}

\begin{abstract}
The coexistence of multiple cultures is a challenge that requires behavioral changes for the health professionals, in particular nurses. This work's objective was to understand the factors and beliefs that influence the demand for health care from immigrants in the Porto metropolitan area (Portugal), and their accessibility to the health services. We developed an exploratory-descriptive qualitative study. We obtained the data through semi-structured interviews of eleven Ukrainian residents of the Porto metropolitan area. We used the twelve cultural domains of Purnell. Sampling was non-probability, of convenience and in "snowball". Participants were required to give their free and informed consent. The results indicated some difficulties accessing health care due to inefficient communication, resulting from the language barrier and/or of different interpretations, and the disarticulation between the different immigrant support services. This study allowed the implementation of strategies designed to promote health care directed to immigrants, taking into consideration the diversity and vulnerability when accessing health services.
\end{abstract}

Keywords: • Legal aspects $\bullet$ Immigrants $\bullet$ Needs $\bullet$ Nurse Care $\bullet$ Beliefs • Interculturality

Correspondence Address: Dalila Brito, Ph.D., Researcher, Portucalense University, Portucalense Institute for Legal Research, R. Dr. António Bernardino de Almeida 541, 4200-072 Porto, Portugal. Idalina Vilela, M.S., Researcher, Portucalense University, Portucalense Institute for Legal Research, R. Dr. António Bernardino de Almeida 541, 4200-072 Porto, Portugal. Noemia Bessa Vilela, M.S., PhD Student, University of Maribor, Faculty of Law, Mladinska ulica 9, 2000 Maribor, Slovenia, email: noemia@upt.pt.

DOI 10.18690/24637955.10.1.71-83(2017) ISSN 2463-7955

(C) 2017 University of Maribor Press

Available at http://journals.um.si/ 


\section{Introduction}

Healthcare is unsafe. Even though, in the past few years many measures have been taken upon in order to increase safety both for healthcare workers, and patients, any improvements are far from being seen. The slow progress is not due to lack of trying. Both public and private organisations have initiated major programmes to develop and implement new safe practices and to train healthcare workers in patient safety - as well as their own-

Leading the way in government commitment to safety, in Europe, we have the UK that has established the "National Patient Safety Agency under the Department of Health" (NPSA), and has developed a reporting system and a clinical assessment service having also established and enforced performance measures. In addition, voluntary efforts, such as the Patient Safety First campaign, have been extensive. Still, all these efforts have proven to be insufficient. Safety does not depend just on measures, practices and rules - not even legal ones - and does not - also depend on any specific improvement methods; it depends on achieving a culture of trust, reporting, transparency and discipline. For healthcare organisations in every country, this requires major culture change.

The profound inequality between countries cause continuous fluxes of human beings from the poorest regions to those with better conditions. The migration phenomenon marks the international agenda (OIM, 2009), is a relevant topic for the community in general and, for the health professionals in particular, because of the necessity to address the basic needs of these groups.

Portugal has hundreds of thousands immigrants. The specific needs of these groups make this population deserving of specific approaches by the health professionals.

In general, those who migrate are healthy, are in a more productive age group but are also vulnerable to disease because of the risks to which they are exposed in the receiving countries (Kandula, 2004) (Lopes L. , 2007) (Backstrom, 2009).

The restrictions of access to health care imposed on illegal immigrants and the fear of this condition being denounced may make them avoid health services and resort to auto-medication, alternative medicines, and services in which documentation is not a determining factor such as emergencies, pharmacies, and mobile units (CCHS, 1997).

On the Ukrainian immigration in Portugal one can observe the phenomenon of lack of social insertion, characterized by a lack of recognition of individual professional qualifications, a factor that greatly affects inclusion (Russo \& Soeiro, 2007). 
As noted by the Commission on Social Determinants of Health (CSDH), (WHO, 2008) nurses and other health professionals must understand their own role in providing equitable and accessible health care. The coexistence of other cultures results in a knowledge deficit for nurses and the other health professionals and requires changes in the practice of care. This process should be based on shared learning that allows nurses to understand the beliefs, values and expectations of their patients in order to create an intervention plan capable of responding to this reality, namely on the access to services, education for health, and health surveillance. Health care in a multicultural setting is an important challenge for nursing under the current world context of human mobility and globalization.

Nurses must develop cultural competences and adopt strategies, congruent behaviors, attitudes and policies that respond to the immigrant patients' needs. The development of these competences is a slow process that requires a chance of thinking and acting from the nurse (Liladar, 1998). However, one can only improve the ability to provide care to people from different cultures if one understands their needs in terms of health. (Brach \& Fraser, 2000:57) (DR 85, 2007-05-03)

Purnell's model for cultural competence is based on theories and research from several disciplines in the areas of humanities and health. It allows the assessment, inside the complexity of cultures and ethnic groups, of values, beliefs, lifestyles, and practices of individuals, families and groups with diverse cultures. This helps to foment trust on the cultural competence of the health professionals (Purnell, 2011).

The available literature highlights the importance of the twelve Purnell domains. They are essential to evaluate the cultural attributes of the individual, family or community, and consist of: Overview/heritage, Communication, Family roles and organization, Workforce issues, Biocultural ecology, High-risk behaviors, Nutrition, Pregnancy and childbearing, Death rituals, Spirituality, Health care practices, and Health care practitioner (Purnell, 2010).

This model values the acceptance of and respect for the individual beliefs and allows health care professionals to act without cultural interference. It favors the knowledge of beliefs and individual care of the patients so that health interventions may be setup taking into consideration the historical-cultural background of the individual (Purnell, 2010). It values the respect for the social and cultural aspects of both actors, the professional and the individual in need of care. It proposes the observance of cultural values to effect an integral care essential for the recovery of the person. If the cultural aspects are not intertwined with the health practices, the patient may feel disrespected by the care provider, causing a disruption of the care (Purnell, 2005).

The model focuses the emic and ethic aspects on the opinions of the patient, the family and the community. The primary characteristics cover nationality, race, gender, skin color, age and religious affiliation. Secondary characteristics focus on 
the socioeconomic status, education level, occupation, physical exercise, political beliefs, urban or rural residence, marital status, sexual orientation, time outside the country, reasons for immigration, legal or illegal situation, physical characteristics. We used this model for our research because its assumptions are a guideline to analyze the fundamental characteristics of a culture, in which the individual may be assessed as a social and cultural being with every cultural symbolism transmitted between generations, in which beliefs, values and practices intermingle for the maintenance of health (Helman, 2009).

Leininger states that cultural care allows the opening to understanding the beliefs and values of patients instead of being a cultural imposition from the professionals (Leininger, 1991).

Nursing will possess culturally congruent and beneficial attitudes when the patient's cultural values become a tool that can be used adequately by the professional. The nurse must develop new cultural perspectives based on three types of cultural care: conservation and maintenance; adjustment and negotiation; and finally, repatterning and restructuring.

\section{$2 \quad$ Methods}

We performed a qualitative exploratory-descriptive study (Fortin, 2009). Sample consisted of Ukrainian immigrants residing in the Porto metropolitan area. Sampling was non-probability or of convenience and in "snowball", obtained with the support of various elements that were known to the target population.

Data was obtained using a script covering the twelve Purnell Cultural domains through a semi-structured interview, conducted using the medium selected by the interviewee. These interviews aimed to explore some phenomenon, identify behaviors, convictions and practices from real situations (Purnell, 2010). Participants were required to give their free and informed consent, and anonymity was guaranteed in order to protect the vulnerable individuals.

We obtained the support of the Association Friends of the Eastern Europe Immigrants and the Orthodox Baptist Church in Porto. Data were collected between February and July 2011 and treated using the Bardin content analysis (Bardin, 2010). This analysis consisted in discovering the sense nucleus that composes a communication which presence or frequency have a meaning for the analyzed subject. The most frequent theme is the unit of significance that emerges naturally from the analyzed text. 


\section{$3 \quad$ Results}

Data are presented sequentially, analyzing each of the twelve Purnell domains. The mode and average interviewee age is 39 , with predominance of the female gender.

For the Overview/heritage domain, the migration phenomenon is explained by the search of a better wage, with better living conditions in the destination country. In the case of the population represented in this study, the main reasons for choosing Portugal as the destination country are, the ease of access to education, the fact that it is a country with a hospitable people, the ease of family reunification, and the climate (Rosário \& Santos, 2008) (Gois, 2010) (Giddens, 2010) (Marques, 2010). They consider schooling and training programs to be "pedagogic capital" that leads then into migration and a sense of investment from which they expect to find future returns. Example of registry unit: "We can't study over there now." (E6); "Back in Ukraine it was very difficult to make enough money for our children's education, here we are much better" (E9).

Concerning Communication, learning Portuguese is necessary for obtaining a resident permit. This means a greater chance of acquiring resources to return to their country of origin. Attending school and learning Portuguese was considered very important since this education is more reliable. "I searched for schools to speak Portuguese. We speak Portuguese but can't read it, and we give a different connotation to the word" (E8).

In this study and in this domain, several beliefs were emphasized, such as: the importance of visual contact during communication; the interdiction of kissing between genders in a professional environment; the use of handshakes in an official environment; the hugging of the female gender being reserved for intimacy.

Family roles and organization - the family is the nucleus and the reason for emigration. The coexistence of different families is frequent in order to divide expenses. "Everything we do in life is for the family. Family is what matters." (E6); "We are very attached to our children, we try to raise them by giving them the best. We provide high quality to our kids." (E9).

Ukrainian families feature a mixed pattern in which the woman is responsible for the acquisition and transfer of ancestral knowledge. From the interviews it was clear that it is up to women to promote care, self-care, family care, and the education of children. In fact, it is a social right in Ukraine for a mother to take care of a child from birth until the baby is three years old. "When a child is born, something good is that we can stay 3 years at home with the child. And we continue to earn money." (E4). 
Through emigration, young people pass from an enlarged family, with all values of knowledge transmission between generations, to a nuclear or mono-parental family, without the traditional support. This can hinder the integration in the host country.

Having left their parents in Ukraine is a concern of immigrants that planned to return after some years of work but that now consider that possibility distant because of the political and economic situation of their country.

The lack of health surveillance of the elderly at the home country is referred by $36 \%$ of interviewees as a concern due to economic difficulties.

Domestic violence is a reality within the Ukrainian family and results from alcoholism related to economic difficulties. The immigrated Ukrainian woman suffers in multiple ways, separation from the family, many are undocumented and can't denounce the aggressions since they are unable to resort to support institutions. Men refer to violence as something natural and reoccurring. "A man, when he can't take care of the family starts drinking and hits his wife." (E1); "Domestic violence arises from economic problems. They are unable to provide for their home, they start having psychological problems and drink." (E9).

Workforce issues - Insertion on the professional world depends on the host's country language proficiency. Interviewees affirm that the linguistic barrier was the most felt difficulty since they consider Portuguese a difficult language.

Because of this, Portuguese language courses are offered to the immigrant community by official entities, civil society, Catholic Church, Private Institutions of Social Solidarity (IPSS), various other associations and organizations, and schools. However, these courses have been proven insufficient, particularly if we take into consideration that language is mentioned - very strongly - as one of the main challenges that the recent and significant Ukrainian immigrant community has to overcome (Serranito \& Santana, 2005) (Baganha, Marques, \& Gois, 2004) (Lyudmila, 2010) (Monteiro, 2006) (Tamayo \& Schwartz, 1993)(Sousa, 2011).

In what concerns the category knowledge of the law, rights and duties, the interviewees mention the absence of knowledge and information of their rights since they came to work and return to their home country as soon as possible: "Ukrainians don't believe that they will stay here very long so they don't deepen their knowledge. They don't try to know their rights." (E11)

Portuguese citizenship is in demand for immigrants because it facilitates their integration but the double nationality is not accepted by their country and so they became foreigners in their own country. "I live in an owned property and we are nationalized Portuguese. It is easier for the bureaucracy since the Portuguese State demands a new tax to work here every 4 years. Documentation is easier, certification 
is easier and therefore it makes it easier to live here." (E11). Around 36\% of interviewees say that work in Portugal is hard and long, compared to the working hours of other countries, namely France.

Ukrainian immigrants demonstrate a great fear of losing their job because they know it is very hard to access work and they have to return to their home country after two years unemployment.

Biocultural ecology - In the history of the Ukrainian people, the period of 19321933 (Holodomor) was marked by famine, freedom was limited and the postindependence crisis led to emigration.

The unemployment status, the irregular work, the fear to lose the job contract, the transition process have an impact on lifestyle, changing the behavior patterns. From the interviewees in our sample, $12 \%$ refer sleep and rest alterations that are consistent with the literature (Monteiro, 2011)(Ponizovsky \& Ritsner, 2004) (Oppedal, 2004)

In this domain, apart from the mental health problems, there are diseases connected to the Chernobyl catastrophe, associated with oncologic sicknesses. Other infirmities mentioned were diabetes, cardiovascular diseases, hypertension, and Sexually Transmitted Infections (STI).

On High-risk behaviors, 55\% of interviewee mentions alcohol ingestion, a habit due to the climate and the Economic-Politic conditions, as the main cause of domestic violence. Some authors defend that the depression that affects the Ukrainian immigrant is masked by the use of alcohol.(Sousa, 2006)(Fonseca \& Silva, 2010)(Malynovska, 2004) (Fernandes, 2007) (Ramos, 2009)

Back in the home country it is culturally accepted to resort to abortion and this reflects well on the discourse of the inquired. Every interviewee mentioned having performed abortions. This decision is almost exclusively up to the woman, regardless of the partner's opinion. According to data from the World Health Organization, Russia has the highest abortion rate in the world (OMS, 2005) The literature suggests that, during her lifetime, each woman will perform, on average, three or more abortions. It should be noted that Ukraine was part of USSR up to 1991.

Nutrition - out of the eleven interviewed, $73 \%$ mentioned a change in eating habits both in the number and composition of meals, explained by the milder climate and accessibility to fresh vegetables, which in turn derives from the higher purchasing power. From the country of origin they keep the excessive use of salt (36\%), of fats and carbon hydrates (27\%). 
Pregnancy and childbearing - in this domain, beliefs based on myths and taboos gain force, tending to manifest themselves on the woman's behavior post-birth (Canteiro \& Martins, 2010).

Ukrainians perceive the marital relationship with one purpose, the gift of children. They mention that for a couple to be perfect they must have at least two children. Infertility is a disappointment and can be a reason for the couple to separate. "A couple will do everything to have children. It doesn't work when they don't have children and usually separate." (E6). Culturally, the spouse doesn't accompany the pregnant to consultation and is not present when the baby is born.

In the same way that information about sexuality is taboo, it is also unusual to give a lot of information during pregnancy. However, mothers and grandmothers in Ukraine are present to help during the birth.

The baby's bath is very important, with the application of herbs in the water to act as a soother. The use of purple powder (potassium permanganate, or gentian violet dye - used during the 60s) to disinfect and prevent diseases. The bellybutton is carefully disinfected, taking particular attention not to get it wet. To soothe and relax the baby they often use massages and singing.

Death rituals - the cultural beliefs in this domain are the least likely to suffer any changes over time. "When a family member dies, he stays at home and in the morning of the third day goes to the cemetery. The entire family and friends get together. The family goes through a period of mourning and for nine days does not watch TV or listen to music." (E3).

The wake lasts for three days and the body is then taken to the cemetery. It is customary to summon a religious representative and the burial is always done according to the church, even if the deceased was not a believer. (E8).

Spirituality - religiosity is very present in the life of Ukrainians. Every interviewee enumerated several activities such as marriage, baptism, Easter and report cult prohibitions from their origin country. "During lent we do not eat foods with animal fat forty days in advance.” (E8).

The Ukrainians that lived close to Russia could not practice any religious cult. They learned to look for their spiritual strength inside of themselves, as if their God was within. "I look for spiritual support inside of me. I do not look for the priest's support." (E8).

Around $78 \%$ of the interviewed refer having spiritual support.

Health care practices - Ukrainians say that during the Soviet Union period, they were used to a health system that was considered "good", controlled, organized, and 
gratuitous. Ukrainian immigrants only resort to healthcare when their popular and traditional practices prove inefficient. The use of complementary medicines is mentioned by $45 \%$ of the interviewed. It should be noted that this practice is culturally accepted in their home country and can also be an acquired behavior that is maintained in the host country, without having to do with a knowledge deficit or any other kind of limitation.

The Representation of professionals, as a resource to solve health problems, was mentioned by $18 \%$ dos the inquired, alluding to the lack of confidence in the health professionals. The Resort to the emergency service grouped three signification subunits. Because they perceive a higher competence of the health professionals $(45 \%)$; and are always treated, in spite of the waiting time $(27 \%)$. In what concerns Accessibility to healthcare centers, the most mentioned units were: very long waiting time for consultation was referred by $36 \%$ of inquired; $27 \%$ mentioned that they do not go to the family doctor; and $9 \%$ do not go to health care centers because they are illegal immigrants.

Beliefs related to birth control methods were: oral contraception was considered harmful by $36 \%$ of the interviewed, and the distrust in condoms by $27 \%$.

The Practice of adherence to abortion is used by Ukrainian women in birth control. $45 \%$ mentioned having done it. "Abortion used to be easily done, nowadays not so much. I have also had an abortion, that part was closed, mothers wouldn't talk about it, and we didn't know anything about it." (E10)

The Obstacles that upset the demand for healthcare are overcome resorting to selfmedication $(27 \%)$, to interpreters and proficient professionals $(18 \%)$, and $9 \%$ referred that they looked for help back in their home country.

Health care practitioners - immigrants that have had contact with health professionals consider Portuguese nurses more competent than their origin country and less dependent of the medical power. They think Portuguese nurses have a more positive empathic relationship, are responsible and interested, and demonstrate professional pride.

One of the interviewees mentioned a mutual unfamiliarity when it comes to the culture in both countries. "The nurse doesn't understand our culture and we do not know her level of knowledge." (E9), proposing suggestions to improve communication: "The nursing consultation must be open, they must explain why things are, and improve trust. Try to place problems that must be solved and personalize the service." (E8).

These results are in accordance with the evidences detected by several authors, in which the present society increasingly demands nurses to be capable of performing 
the care process with a greater efficiency, to be more knowledgeable, to be better equipped to respond to the problems of the population, and to possess a greater competence, technically speaking, both in teaching and culturally. (Margato, 2005) (Pereira, 2007)

\section{Implications for the practice of care}

Knowing the challenges and taking into account the indicators found, we developed strategies capable of bridging the information deficit of both the professionals and immigrants on the influence area of the Hospital Center of Vila Nova de Gaia/Espinho, were we exercise our professional functions.

The members of the various services acquired knowledge on the current legislation and on the support structures. This allowed the constitution of a nurse group of reference in what concerns proximity services for care. At the service level, actualized and pertinent information was made available on the support structures, to be used whenever a linguistic barrier is predicted during the care of the immigrant patient.

With the support of the Regional Health Administration the project was extended to every immigrant organizations from the metropolitan area of Porto, and support material was made available to Health Care Centers.

At the Hospital of Vila Nova de Gaia/Espinho the immigrant Guide to Health Access and the informative leaflets in five languages (Portuguese, Russian, Spanish, English, and French) are available and accessible to every professional, on the intranet.

\section{$5 \quad$ Conclusion/suggestion}

The assumption that we are all subject of needs without considering the different cultural contexts, beliefs and values that are specific to each individual and each social group, results in a deficient care practice.

Health professionals must know in detail the culture, lifestyles, habits, and rituals of every person, family or community.

The Ukrainian immigrant may be exposed to a greater vulnerability in what concerns diseases and health problems, due to the impact of the differences in the physical and social environment, the culture and habits, the linguistic barriers, the differences in the administrative and legal systems, among others.

The interviews made possible the conclusion that the demand for health care focuses on hospital emergencies because they feel safer and the care is faster and more efficient, in particular to the illegal immigrant. However, there is no follow-through 
on how the disease progresses, increasing the risks to the individual and the community. Ukrainian immigrants have a positive opinion on nurses and they consider them better prepared than the same professionals in their home country. However, they consider that professionals are unknowledgeable of their culture and the immigrant rights when it comes to access health in the host country.

The health professional must understand the integration processes of the immigrant and possess information that will allow the construction of health diagnostics.

To perform a health diagnostic in the context of immigration, the nurse must possess competences that allow culturally congruent cares.

During the interviews, the immigrants mentioned that both the health professionals and the immigrants have an information deficit, related to the right to health heralded in Portugal.

Information was made available for the use of the health professionals and foreign patients - The immigrant Guide to Health Access and informative leaflets in Portuguese, Russian, Spanish, English, and French.

The required transformations comprise a major culture change for healthcare. Achieving the goal of correctly and safely dealing with minorities will require enlightened leadership, commitment and support from all stakeholders. Any progress in making healthcare safe will continue to sputter unless all the necessary changes are effectively undertaken.

\section{References}

Backstrom, B. (2009) Sáude e Imigrante: As representações e as práticas sobre a saúde e a doença na Comunidade Cabo-Verdiana, 1st ed. (Lisboa: ACIDI).

Baganha, I., Marques, J. \& Gois, P. (2004) The unforeseen wave: migration from the Ucraine: The last ten years, In: Baganha, M. I \& Fonseca, M. L. (eds.) New waves: Migration from Eastern to Southern Europe (Lisbon: Luso-American Foundation).

Bardin, L. (2010) Análise de Conteúdo (Lisboa, Portugal: Edições 70).

Brach, C. \& Fraser, I. (2000) Can Cultural Competency Reduce Racial and Ethnic Health Disparities? A Review and Conceptual Model, Medical Care Research \& Review, 57(Suppl. 1), pp. 181-217.

Canteiro, E. \& Martins, M. (2010) A maternidade, Crenças e tradições. (Granada: Braga).

CCHS. (1997) Health Care for Children of Immigrant Families, Pediatrics, 100(1), pp. 153156.

DR 85 SerieI- Resolução do Conselho de Ministros (2007-05-03). O Plano para a Integração dos Imigrantes (PII). n. ${ }^{\circ}$ 63-A.

Fernandes, et. al. (2007) A Imigraçao e o acesso à saúde. Boas práticas identificadas em dois projectos de intervençao na area da saúde, In Dias S. (ed.). Revista migrações, $\mathrm{n}^{\circ} 1$ (Numero temático imigrações e saúde - Setembro). 
Fonseca, M. \& Silva, S. (2010) Saude e Imigraçao: Utentes e Serviços na área de influencia do Centro de Saúde da Graça (Lisboa: Estudos OI).

Fortin, M. F. (2009) O Processo de Investigaçao: Da concepçao à realizaçao (Loures: Lusodidata).

Giddens, A. (2010) O mundo na Era da Globalizaçao. $7^{\circ}$ ed. (Lisboa: Editorial Presença).

Gois, M. et al. (2010) Imigraçao Ucraniana: a emergencia de uma de várias comunidades? (Lisboa: ACIDI).

Helman, C. (2009) Cultura, saúde e doença, $2^{\mathrm{a}}$ ed. (Porto Alegre:Artes Médicas).

Kandula, N. (2004) Assuring the health of immigrants: what the leading health indicators tell us, Annual Review Of Public Health, 25, pp. 357-376, doi: 10.1146/annurev.publhealth.25.101802.123107

Leininger, M. (1991) Culture care diversity and universitaly: A theory of nursing (New York: National League for Nursing Press).

Lopes, L. (2007) Gravidez e Seropositividade em mulheres imigrantes na região, $1^{\mathrm{a}}$ ed. (Lisboa: ACIDI).

Lyudmila, B. (2010) Seminario de Boas Práticas- Saudar, Género e Imigração (Coimbra: Saudar-Graal).

Malynovska, O. (2004) International labour migration from the Ukraine: the last ten years, In: Baganha, I. \& Fonseca, M. L. (eds) New waves: Migration from Eastern to Southern Europe (Lisboa: Fundaçao Luso -Americana).

Margato, C. (2005) A visibilidade dos Cuidados de Enfermagem (Vol. 62) (Coimbra: Sinais vitais).

Marques et al. (2010) Imigraçao ucraniana em Portugal e no sul da Europa: A emergência de uma ou vária comunidades?, $1^{\text {a }}$ ed. (Lisboa: ACIDI).

Monteiro, A. (2006) Imigração e Saúde - Imigrantes da Europa de Leste em Portugal, Revista Científica da Universidade de Investigação em Ciências da Saúde, 2, pp. 9-20.

OIM (2009) Organização Internacional das Migrações (Geneve: OIM).

OMS (2005) Relatório do controlo de natalidade na Uniao Sovietica (New York: UN).

Oppedal, B., Røysamb E. \& Sam, D. L. (2004) The effect of acculturation and social support on change in mental health among young immigrants, International Journal of Behavioral Development, 28(6), pp. 481-494, doi: 10.1080/01650250444000126.

Pereira, M. (2007) Satisfação dos utentes do centro de saúde de Mogadouro, face aos cuidados de enfermagem (Vol. 71) (Coimbra: Sinais vitais).

Ponizovsky, A. \& Ritsner, M. (2004) Patterns of loneliness in an immigrant population, Comprehensive Psychiatry, 45(5), pp. 408-414, doi: 10.1016/j.comppsych.2004.03.011.

Purnell, et. al. (2011) A guide to developing a culturally competent organization, Journal of Transcultural Nursing, 22(1), pp. 7-14, doi: 10.1177/1043659610387147.

Purnell, L. (2005) The Purnell model for Cultural Competence, Journal of Multicultural Nursing \& Health, 11(2), pp. 7-15.

Purnell, L. \& Paulanka, B. (2010) Cuidados de Saúde Transculturais - Uma Aborgagem Culturalmente Competente, 3 ed. (Amadora: Lusodidata).

Ramos, N. (2009) Multiculturalidade - Perspectivas de Enfermagem- Contributos para Melhor Cuidar (Loures: Lusociencia).

Rosário, E. \& Santos, T. (2008) Quanto custa ser imigrante? (Lisboa: Estudos OI 26.ACIDI).

Russo, H. \& Soeiro, A. (2007) Imigrants de Leste-Vivencias Diferentes num espaço Comum (Espanha: Autonomia).

Serranito, V. \& Santana, P. (2005) Percursos de vida de imigrantes de Leste, In: SOS racismo (ed.) Imigração e Etnicicidade. Vivência, e Trajetórias de mulheres em Portugal (Lisboa: SOS racismo). 
Sousa, J. E. (2011) Imigrantes ucranianos em Portugal- Satisfação das necessidades de imigração á adaptação de comportamentos saudáveis (Lisboa: Universidade Aberta).

Sousa, J. (2006) Os imigrantes Ucranianos em Portugal e os cuidados de Saúde (Lisboa: Acime).

Tamayo, A. \& Schwartz, S. (1993) Estrutura motivacional dos valores humanos, Psicologia: Teoria e Pesquisa, 9(2), pp. 329-348

WHO (2008) Closing the Gap in a Generation: Health equity through action on the social determinants of health. Geneva, available at: http://www.who.int/ageing/publications/global_health/en/index.html (March 13, 2017). 
\begin{tabular}{l|l}
84 & MEDICINE, LAW \& SOCIETY
\end{tabular} 